\title{
Atividade saprofítica de Rhizoctonia em solos do Nordeste brasileiro e relação com propriedades físicas, químicas e microbiológicas
}

\author{
Saprophytic activity of Rhizoctonia in Northeastern Brazilian soils and relationship with physical, \\ chemical and microbiological properties
}

Actividad saprofita de Rhizoctonia en suelos del Nordeste brasileño y relación con propiedades

físicas, químicas y microbiológicas

\section{Resumo}

O fungo Rhizoctonia pode sobreviver no solo por longos períodos sem plantas hospedeiras e condições favoráveis, quase exclusivamente na forma de micélio ativo e escleródios, sendo essa estratégia denominada colonização saprofítica. Este trabalho teve como objetivos avaliar a atividade saprofítica de Rhizoctonia em 52 amostras de solos da região Nordeste do Brasil e analisar a relação das propriedades físicas, químicas e microbiológicas dos solos com essa atividade. Nesse estudo, a atividade saprofítica foi avaliada com iscas de segmentos de talos de feijão-caupi e foi detectada em 38,5\% das amostras de solo. Não houve influência significativa do tipo de cobertura do solo na época de coleta e da classe textural dos solos no percentual de colonização saprofítica. Foram constatas correlações positivas e significativas $(\mathrm{P}<0,01)$ da atividade saprofítica de Rhizoctonia com os teores de fósforo $(\mathrm{r}=0,80)$, potássio $(\mathrm{r}=0,54)$ e atividade hidrolítica do diacetato de fluoresceína $(\mathrm{r}=0,51)$. Com esses resultados, foi possível estabelecer uma relação entre o potencial de supressividade ou conducividade de alguns solos e o saprofitismo de Rhizoctonia.

Palavras-chave: Fungos do solo; Microbiologia do solo; Atividade de enzimas no solo.

\begin{abstract}
The fungus Rhizoctonia can survive in the soil for long periods without host plants and favorable conditions, almost exclusively in the form of active mycelium and sclerotia, this strategy being called saprophytic colonization. This study aimed to evaluate the saprophytic activity of Rhizoctonia in 52 soil samples from the Northeast region of Brazil and to analyze the relationship between physical, chemical and microbiological properties of soils with this activity. In this study, saprophytic activity was evaluated by baits with segments of cowpea stalks and was detected in $38.5 \%$ of the soil samples. There was no significant influence of the type of soil cover at the time of collection and the textural class of soils on the percentage of saprophytic colonization. There were positive and significant correlations $(\mathrm{P} \leq 0.01)$ of the saprophytic activity of Rhizoctonia with the levels of phosphorus $(\mathrm{r}=0.80)$, potassium $(\mathrm{r}=0.54)$ and
\end{abstract}


hydrolytic activity of fluorescein diacetate $(r=0.51)$. With these results, it was possible to establish a relationship between the suppressive or conductive potential of some soils and the saprophytism of Rhizoctonia

Keywords: Soilborne fungi; Soil microbiology; Enzymes activity in soil.

\section{Resumen}

El hongo Rhizoctonia puede sobrevivir en el suelo por largos periodos sin plantas hospedantes y condiciones favorables, casi exclusivamente en forma de micelio y esclerocios activos, denominándose a esta estrategia colonización saprofita. Este estudio tuvo como objetivo evaluar la actividad saprofita de Rhizoctonia en 52 muestras de suelo de la región Nordeste de Brasil y analizar la relación entre las propiedades físicas, químicas y microbiológicas del suelo con esta actividad. En este estudio, la actividad saprofita se evaluó con cebos de segmentos de tallos de caupí y se detectó en el 38,5\% de las muestras de suelo. No hubo influencia significativa del tipo de cobertura del suelo al momento de la colecta y la clase textural de los suelos sobre el porcentaje de colonización saprofita. Hubo correlaciones positivas y significativas $(\mathrm{P} \leq 0.01)$ de la actividad saprofita de Rhizoctonia con los niveles de fósforo $(\mathrm{r}=0.80)$, potasio $(\mathrm{r}=0.54)$ y actividad hidrolítica del diacetato de fluoresceína $(\mathrm{r}=0.51)$. Con estos resultados fue posible establecer una relación entre el potencial supresor o conductivo de algunos suelos y el saprofitismo de Rhizoctonia.

Palabras clave: Hongo del suelo; Microbiología del suelo; Actividad de las enzimas en el suelo.

\section{Introdução}

O fungo do gênero Rhizoctonia é um habitante do solo e tem sido registrado em todos os tipos de solo em nível mundial (Ogoshi, 1987; Sneh et al., 1991). Dentre as espécies descritas, Rhizoctonia solani Kühn [teleomorfo Thanatephorus cucumeris (Frank) Donk] apresenta destaque por ser cosmopolita, possuir ampla gama de hospedeiros e causar importantes doenças na maioria das plantas cultivadas em todo o mundo (Sneh et al., 1991; Ogoshi, 1996; Agarwal, 2010; Yang et al., 2012; Ajayi-Oyetunde et al., 2018; Farr et al., 2022).

O controle de Rhizoctonia é muito difícil, principalmente, devido à elevada agressividade do patógeno, transmissibilidade pelas sementes e alta capacidade de sobrevivência no solo mesmo na ausência da planta hospedeira (Leach et al., 1970; Agarwal, 2010; Ajayi-Oyetunde et al., 2018). Essa estratégia de sobrevivência é denominada colonização saprofítica e pode ocorrer pela colonização da matéria orgânica em decomposição, por propágulos produzidos sexuada ou assexuadamente, pela colonização de plantas voluntárias e suscetíveis ao patógeno, ou pela colonização da planta sem induzir o aparecimento de sintomas nas mesmas (Garrett, 1956). Rhizoctonia pode prosperar como saprófita no solo graças à sua capacidade de degradar açúcar simples, celulose e hemicelulose, explorando efetivamente uma grande gama de tipos de materiais orgânicos (Croteau et al., 1998; Yulianti et al., 2006; Copley et al., 2015; Bonanomi et al., 2020). A habilidade saprofítica de Rhizoctonia não depende apenas da taxa de crescimento, mas também da produção de antibióticos, toxinas ou enzimas, e outros determinantes do ecossistema do solo, como fatores bióticos e abióticos (Garrett, 1970; Otten \& Gilligan, 1998; Otten et al., 2005; Yulianti et al., 2006).

A quantificação da atividade saprofítica de Rhizoctonia no solo pode ser realizada por diversos métodos (Carling et al., 1992; Dhingra et al., 1995; Neate et al., 1996), mas a utilização de iscas tem propiciado resultados excelentes (Paulitz et al.,, 2005; Sanfuentes et al., 2007; Babiker et al., 2011; Spurlock et al., 2015), inclusive sendo observadas correlações positivas significativas entre os níveis detectados pelo ensaio com iscas e os níveis quantificados por PCR em tempo real (qPCR) (Harries et al., 2020).

Na natureza, a fase saprofítica de Rhizoctonia é seguida por uma fase patogênica (Yulianti et al., 2007). Portanto, os propágulos detectados no solo através de iscas podem ser responsáveis por elevados índices de severidade da doença, como constatado em cultivos de soja e arroz nos Estados Unidos da América (Spurlock et al., 2015), e de fumo na Argentina (Harries et al., 2020). 
A atividades saprofítica de Rhizoctonia pode ser influenciada direta e indiretamente pelas propriedades biológicas, físicas e químicas dos solos, motivo pelo qual o conhecimento dessas propriedades é fundamental na adoção de estratégias adequadas de manejo das doenças (Baker et al., 1970; Otten et al., 1998; Yulianti et al., 2007; Harries et al., 2020).

Como não existem estudos sobre atividade saprofítica de Rhizoctonia em solos brasileiros, o presente trabalho teve como objetivo avaliar a atividade saprofítica desse fungo em solos do Nordeste brasileiro, bem como analisar a relação das características físicas, químicas e microbiológicas dos solos com essa atividade.

\section{Metodologia}

\subsection{Solos}

Baseado no Mapa de Solos do Brasil (Geoinfo, 2014), foram selecionadas 52 áreas para coleta de amostras de solos nos estados de Alagoas, Pernambuco, Paraíba e Rio Grande do Norte (Tabela 1). Em cada área foi registrado o tipo de cobertura do solo e coletadas, aleatoriamente, cinco sub-amostras de $3 \mathrm{~kg}$ de solo a uma profundidade de $0-20 \mathrm{~cm}$, distanciadas de aproximadamente 50 metros. As sub-amostras foram misturadas para constituir uma amostra composta de $15 \mathrm{~kg}$.

\subsection{Análises físicas e químicas dos solos}

As amostras de solo foram secas em temperatura ambiente em local coberto durante 10 dias e depois peneiradas para retirada de resíduos, sendo mantidas em sacos de nylon até o processamento. As amostras de solo foram analisadas quanto aos percentuais de areia, argila e silte. As análises químicas foram: pH da solução do solo, determinado em solução de cloreto de

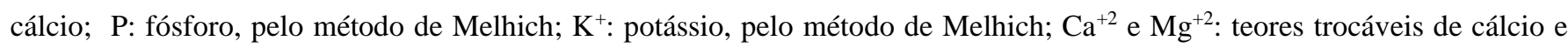
magnésio, respectivamente, em $\mathrm{KCl} ; \mathrm{Al}^{+3}$ : alumínio trocável, extraído por solução de cloreto de potássio a $1 \mathrm{~mol} \mathrm{~L}^{-1} ; \mathrm{H}+\mathrm{Al}$ : acidez total do solo, determinada em solução tampão SMP a pH 7,5; MO: matéria orgânica, determinação por método colorimétrico; $\mathrm{SB}$ : soma de bases $\left(\mathrm{K}^{+}+\mathrm{Ca}^{+2}+\mathrm{Mg}^{+2}\right)$; $\mathrm{CTC}$ : capacidade de troca catiônica $\left(\mathrm{K}^{+}+\mathrm{Ca}^{+2}+\mathrm{Mg}^{+2}+\mathrm{H}+\mathrm{Al}\right)$; $\mathrm{V}$ : saturação por bases do solo (relação $\mathrm{SB} / \mathrm{CTC}$ ); m: saturação por alumínio [relação $\mathrm{Al}^{+3}+/\left(\mathrm{SB}+\mathrm{Al}^{+3}\right)$ ]. Todas as análise foram realizadas conforme metodologias descritas em Donagema et al. (2011).

\subsection{Análises microbiológicas dos solos}

As amostras de solo foram armazenadas em sacos plásticos a $5{ }^{\circ} \mathrm{C}$ e processadas em até duas semanas. As análises microbiológicas incluíram estimativas das densidades populacionais de microrganismos (fungos totais, bactérias totais, bactérias formadoras de endósporo, bactérias copiotróficas e bactérias oligotróficas), respiração basal da população microbiana, atividade enzimática pela hidrólise do diacetato de fluoresceína e pela fosfatase ácida, e diversidade funcional de comunidades bacterianas.

As densidades populacionais de microrganismos foram analisadas usando diluições em série e plaqueamentos em meios de cultura. De cada amostra de solo foi retirada uma alíquota de $10 \mathrm{~g}$ e transferida para recipiente com $90 \mathrm{~mL}$ de água destilada esterilizada. Após homogeneização em agitador Vortex por 5 minutos, foram efetuadas diluições em série e as suspensões distribuídas em diferentes meios de cultura: batata-dextrose-ágar (BDA) (Tuite, 1969) com 250 ppm de tetraciclina para fungos totais; ágar nutritivo-dextrose-extrato de levedura (NYDA) (Tuite, 1969) para bactérias totais; meios para bactérias copiotróficas (MBC) e oligotróficas (MBO) (Semenov et al., 1999); ágar nutritivo (AN) (Dhingra \& Sinclair, 1995) para bactérias formadoras de endósporo, sendo que antes do plaqueamento as diluições foram submetidas à banho-maria de $80{ }^{\circ} \mathrm{C}$ por $20 \mathrm{~min}$ (Sneath, 1986). As placas foram incubadas a $25 \pm 1{ }^{\circ} \mathrm{C}$ no escuro. As populações bacterianas foram avaliadas após 48 horas de incubação, enquanto a fúngica após cinco dias de incubação. Cada população resultou do número médio de colônias em cinco placas, sendo expressas em unidades formadoras de colônias por grama de solo (ufc) $\mathrm{g}^{-1}$ de solo. 
A respiração basal da população microbiana no solo foi determinada pela quantificação do dióxido de carbono $\left(\mathrm{CO}_{2}\right)$ liberado no processo de respiração microbiana (evolução de $\mathrm{CO}_{2}$ ) pelo método de adsorção alcalina, com a umidade das amostras de solo ajustadas para 60\% de sua capacidade de campo (Anderson \& Domsch, 1990). Das amostras de solo foram retiradas alíquotas de $50 \mathrm{~g}$ e colocadas em recipientes hermeticamente fechados, individualmente, onde o $\mathrm{CO}_{2}$ produzido foi capturado por solução de $\mathrm{NaOH} 0,5 \mathrm{~mol} \mathrm{~L}^{-1}$. Após 48 horas de incubação, o $\mathrm{CO}_{2}$ foi quantificado por titulação com $\mathrm{HCl} 0,25$ mol L ${ }^{-1}$, precedida pela adição de solução de cloreto de bário $\left(\mathrm{BaCl}_{2} 0,05 \mathrm{~mol} \mathrm{~L}{ }^{-1}\right)$ à solução de $\mathrm{NaOH}$, e fenoftaleína diluída em $100 \mathrm{~mL}$ de álcool etílico $(95 \%, \mathrm{v} / \mathrm{v})$ como indicador de pH. As determinações foram efetuadas em triplicatas. A respiração basal foi expressa em mg de $\mathrm{CO}_{2}$ evoluído $\mathrm{kg}^{-1}$ de solo.

A atividade da enzima fosfatase ácida (PAC) foi determinada conforme Tabatabai (1994), incubando-se $1 \mathrm{~g}$ de solo em $4 \mathrm{ml}$ de tampão universal modificado (MUB, pH 6,0) e $1 \mathrm{~mL}$ de $p$-nitrofenil fosfato $(0,05 \mathrm{~N})$, por 1 hora a 37 ' C. Após incubação, adicionaram-se $1 \mathrm{~mL}$ de $\mathrm{CaCl}_{2}(0,5 \mathrm{M})$ e $4 \mathrm{~mL}$ de $\mathrm{NaOH}(0,5 \mathrm{M})$ para finalização da reação. O conteúdo dos frascos foi homogeneizado e passado em papel de filtro Whatman $\mathrm{n}^{\circ} 2$, procedendo-se a leitura da absorbância do filtrado em

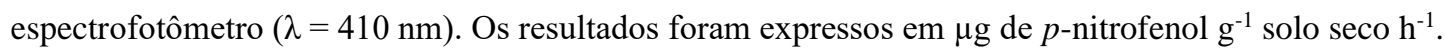

A velocidade de hidrólise do diacetato de fluoresceína (3',6'- diacetilfluoresceína) (FDA) foi determinada conforme Schruner \& Rosswall (1982). Amostras de $1 \mathrm{~g}$ de solo foram incubadas em tampão fosfato de sódio $(60 \mathrm{mM}$, pH 7,6) e agitadas por 15 minutos. A seguir, $100 \mu \mathrm{L}$ do substrato (diacetato de fluoresceína, $4.8 \mathrm{~m} M$ ) foram adicionados à suspensão de solo e estas incubadas por 2 horas, a $25^{\circ} \mathrm{C}$, sob agitação $(180 \mathrm{rpm})$. A reação foi finalizada com a adição de $20 \mathrm{~mL}$ de acetona pura. O conteúdo do frasco foi centrifugado (6000 rpm, 5 minutos) e filtrado em papel Whatman $\mathrm{n}^{\circ} 4$. A absorbância do filtrado foi determinada por espectrofotometria $(\lambda=490 \mathrm{~nm})$. Os resultados foram expressos em $\mu \mathrm{g}$ de fluoresceína $\mathrm{g}^{-1}$ solo

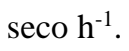

Controles adequados para descontar a absorbância não derivada das reações, curvas padrões para conversão de leituras espectrofotométricas em massa de produto formado e análises em duplicatas foram empregados para todas as três avaliações enzimáticas.

A estrutura funcional das comunidades microbianas do solo foi determinada por meio da análise do perfil catabólico em placas multipoços Biolog EcoPlate ${ }^{\circledR}$ (Biolog, Inc. Hayward, EUA), conforme descrito em Garland (1996). Cada placa contém triplicatas de 31 substratos e um controle negativo, correspondente a um poço sem fonte de carbono. As placas foram inoculadas com $150 \mu \mathrm{L}$ de uma suspensão de solo (1:100) em cada poço e incubada a $25^{\circ} \mathrm{C}$. A absorbância dos poços foi quantificada em leitor multiplacas (Microplate E-Max (Bio-Rad, Richmond, EUA) a 578 nm nos tempos de 0 e 48 horas de incubação. O incremento da absorbância entre os tempos de incubação de 0 e 48 horas, observado para cada substrato, foi corrigido pela subtração do incremento ocorrido neste mesmo período dos respectivos controles sem fonte de carbono. Quando diferenças negativas foram obtidas atribuiu-se o valor zero. Os valores de incremento de absorbância corrigidos (IAC) foram utilizados para quantificar o potencial de degradação dos substratos pela comunidade microbiana. Para minimizar o efeito de diferentes densidades de células, os dados foram normalizados pela divisão dos IAC de cada substrato pela soma dos IAC dos 31 substratos dentro de cada amostra. Os dados dos perfis catabólicos foram utilizados para determinação dos índices de riqueza $(\mathrm{R})$, equitabilidade $(\mathrm{E})$ e diversidade $(\mathrm{H})$ da comunidade microbiana, conforme Zak (1994). A riqueza foi definida como o total de substratos utilizados por amostra. A diversidade foi calculada pelo índice de Shannon como $\mathrm{H}=-\Sigma$ $(\mathrm{Pi} * \ln (\mathrm{Pi}))$, onde Pi é a proporção representada pela atividade catabólica sobre cada substrato (i) relativa ao total da amostra. A equitabilidade foi expressa como $\mathrm{E}=\mathrm{H} / \mathrm{ln}(\mathrm{R})$. Conceitualmente, diversidade é a variedade de espécies em uma comunidade, riqueza de espécies representa o número total de indivíduos constituintes da comunidade e equitabilidade de espécies corresponde à distribuição de indivíduos dentro do que são consideradas populações (Tótola \& Chaer, 2002). 


\subsection{Atividade saprofítica de Rhizoctonia nos solos}

Na determinação da atividade saprofítica de Rhizoctonia foram utilizadas iscas biológicas, constituídas de segmentos de talos de feijão-caupi [Vigna unguiculata (L.) Walp.] (cultivar IPA 206) com $1 \mathrm{~cm}$ de comprimento. Os talos foram autoclavados $\left(120^{\circ} \mathrm{C}, 1 \mathrm{~atm}, 30\right.$ minutos) e depois imersos em uma suspensão de tetraciclina (250 ppm). Após secagem por 30 minutos em câmara asséptica, 16 talos foram semeados em cada recipiente plástico tipo gerbox $(13 \times 13 \times 4 \mathrm{~cm})$ contendo 250 $\mathrm{g}$ de solo, previamente peneirado em uma malha de $4 \mathrm{~mm}$ e umedecido com $50 \mathrm{~mL}$ de água destilada esterilizada. $\mathrm{O}$ delineamento experimental foi inteiramente casualizado, com 52 tratamentos (amostras de solos) e oito repetições, sendo cada repetição representada por um gerbox. Após dois dias de incubação no escuro a $25 \pm 1{ }^{\circ} \mathrm{C}$ e umidade relativa de $75 \pm 5,5 \%$ em câmara de crescimento do tipo BOD, os talos foram recuperados pela passagem do solo em peneira com malha de 1,7 mm e lavados em água destilada esterilizada. Após secagem por 30 minutos em papel de filtro esterilizado, oito talos foram transferidos para cada placa de Petri contendo o meio de Ko \& Hora (1971) modificado, com a substituição de $50 \mathrm{mg}$ do fungicida Dexon (fenaminosulf) por 0,001 mg do fungicida Benlate (benomyl). Decorridas 24 horas de incubação no escuro a $25 \pm 1{ }^{\circ} \mathrm{C}$, foi efetuada a contagem do número de talos que proporcionaram o crescimento de Rhizoctonia no meio de cultura, sendo calculada a porcentagem de colonização saprofítica gerbox ${ }^{-1}$ (CLS).

Adicionalmente, foram efetuadas preparações microscópicas em lâminas de vidro, dos crescimentos fúngicos no meio de cultura originados das iscas, para observação das características morfológicas.

\subsection{Análises dos dados}

Os dados de CLS foram transformados em $(x+0,5)^{1 / 2}$ e submetidos à análise de variância (ANOVA), sendo as médias agrupadas pelo teste de Scott-Knott, ao nível de 5\% de probabilidade ( $\mathrm{P}=0,05)$. Visando comparar os dados médios de CLS em relação ao tipo de cobertura do solo na época de coleta e à classe textural do solo, foi realizado o teste de Kruskal-Wallis $(\mathrm{P}=0,05)$. Para caracterizar os possíveis fatores envolvidos na supressividade e/ou conducividade dos solos à atividade saprofítica de Rhizoctonia, foram efetuadas comparações dos valores médios de CLS com os valores das variáveis físicas, químicas e microbiológicas determinadas para cada amostra de solo que evidenciou colonização saprofítica, pela análise de correlação de Pearson, ao nível de $1 \%$ de probabilidade $(\mathrm{P}=0,01)$.

\section{Resultados}

Foi detectada atividade saprofítica de Rhizoctonia em 38,5\% das amostras de solo, com níveis de colonização saprofítica (CLS) variando de 3,3\% a 86,4\% (Tabela 1). Em 45\% dessas amostras foram constatados valores de CLS de até 20,0\%, valores de CLS entre 21 e 40 foram verificados em 35\% das amostras, enquanto valor de CLS superior a $80 \%$ foi constatado somente em uma amostra (CAR-1).

Pela análise de agrupamento de Scott-Knott, houve diferença significativa $(\mathrm{P} \leq 0,05)$ entre os solos quanto aos valores de CLS. Os solos foram separados em cinco grupos distintos de similaridade, sendo o primeiro grupo composto pelos dois solos que apresentaram maiores valores de CLS (CAR-1 e CGE-1) e o último pelos 32 solos que não apresentaram nenhum nível de atividade saprofítica de Rhizoctonia. 
Tabela 1. Atividade (colonização) saprofítica de Rhizoctonia em solos do Nordeste brasileiro.

\begin{tabular}{|c|c|c|c|c|c|}
\hline Código do solo & Município & $\mathbf{U F}^{\mathbf{a}}$ & Classe textural $^{\mathbf{b}}$ & Cobertura $^{\mathrm{c}}$ & Colonização saprofítica (\%) \\
\hline ARE-1 & Arez & $\mathrm{RN}$ & $\mathrm{ArFr}$ & cana-de-açúcar & $13,3 \mathrm{~d}$ \\
\hline ARE-2 & Arez & $\mathrm{RN}$ & $\mathrm{Ar}$ & vegetação secundária & $0,0 \mathrm{e}$ \\
\hline BEZ-1 & Barreiros & PE & FrAgAr & vegetação secundária & $10,0 \mathrm{~d}$ \\
\hline BEZ-2 & Bezerros & PE & FrAr & tomate & $0,0 \mathrm{e}$ \\
\hline BEZ-3 & Bezerros & PE & $\mathrm{ArFr}$ & milho & $0,0 \mathrm{e}$ \\
\hline BEZ-4 & Bezerros & PE & FrAr & vegetação secundária & $0,0 \mathrm{e}$ \\
\hline BJA-1 & Bom Jardim & PE & FrAgAr & banana & $3,3 \mathrm{~d}$ \\
\hline BOM-1 & Bonito & PE & FrAgAr & inhame & $43,3 \mathrm{~b}$ \\
\hline CAM-1 & Camaragibe & $\mathrm{PE}$ & FrAgAr & milho & $8,3 \mathrm{~d}$ \\
\hline CAM-2 & Camaragibe & PE & FrAgAr & mata & $20,8 \mathrm{c}$ \\
\hline CAM-3 & Camocim de São Félix & PE & FrAgAr & milho & $39,1 \mathrm{~b}$ \\
\hline CAN-1 & Canguaretama & $\mathrm{RN}$ & FrAgAr & vegetação secundária & $0,0 \mathrm{e}$ \\
\hline CAR-1 & Carpina & PE & FrAr & cana de açúcar & $86,4 \mathrm{a}$ \\
\hline CGD-1 & Campina Grande & PB & FrAgAr & brachiaria & $0,0 \mathrm{e}$ \\
\hline CGD-2 & Campina Grande & PB & FrAgAr & milho & $26,7 \mathrm{c}$ \\
\hline CGD-3 & Campina Grande & PB & FrAgAr & milho & $0,0 \mathrm{e}$ \\
\hline CGE-1 & Chá Grande & PE & FrAgAr & rabanete & $56,7 \mathrm{~b}$ \\
\hline CGE-2 & Chá Grande & PE & FrAgAr & couve & $79,2 \mathrm{a}$ \\
\hline $\mathrm{CON}-1$ & Conde & $\mathrm{PB}$ & $\mathrm{ArFr}$ & brachiaria & $0,0 \mathrm{e}$ \\
\hline ESP-1 & Espírito Santo & $\mathrm{RN}$ & FrAr & milho & $0,0 \mathrm{e}$ \\
\hline ESP-2 & Espírito Santo & $\mathrm{RN}$ & $\mathrm{ArFr}$ & vegetação secundária & $20,8 \mathrm{c}$ \\
\hline ESP-3 & Espírito Santo & $\mathrm{RN}$ & $\mathrm{Ar}$ & cana de açúcar & $0,0 \mathrm{e}$ \\
\hline GOI-1 & Goiana & $\mathrm{PE}$ & $\mathrm{ArFr}$ & sem cobertura & $0,0 \mathrm{e}$ \\
\hline GOI-2 & Goiana & PE & FrAgAr & mandioca & $0,0 \mathrm{e}$ \\
\hline GOI-3 & Goiana & $\mathrm{PE}$ & $\mathrm{Ag}$ & cana de açúcar & $0,0 \mathrm{e}$ \\
\hline GOI-4 & Goiana & $\mathrm{PE}$ & FrAr & mata atlântica & $0,0 \mathrm{e}$ \\
\hline GON-1 & Goianinha & $\mathrm{RN}$ & $\mathrm{ArFr}$ & cana de açúcar & $17,4 \mathrm{~d}$ \\
\hline IGA-1 & Igarassu & $\mathrm{PE}$ & FrAgAr & cana de açúcar & $0,0 \mathrm{e}$ \\
\hline MAM-1 & Mamanguape & PB & $\mathrm{ArFr}$ & mata & $0,0 \mathrm{e}$ \\
\hline MAM-2 & Mamanguape & PB & FrAr & sem cobertura & $0,0 \mathrm{e}$ \\
\hline MAR-1 & Maragogi & $\mathrm{AL}$ & FrAgAr & capim & $12,5 \mathrm{~d}$ \\
\hline NAT-1 & Natal & $\mathrm{RN}$ & $\mathrm{Ar}$ & vegetação secundária & $0,0 \mathrm{e}$ \\
\hline NAT-2 & Natal & $\mathrm{RN}$ & $\mathrm{Ar}$ & vegetação secundária & $0,0 \mathrm{e}$ \\
\hline PAR-1 & Parnamirim & $\mathrm{RN}$ & FrAr & vegetação secundária & $0,0 \mathrm{e}$ \\
\hline PAS-1 & Passira & $\mathrm{PE}$ & FrAg & milho & $31,0 \mathrm{c}$ \\
\hline PAS-2 & Passsira & $\mathrm{PE}$ & FrAgAr & mata & $0,0 \mathrm{e}$ \\
\hline PCA-1 & Porto Calvo & $\mathrm{AL}$ & FrAgAr & cana de açúcar & $0,0 \mathrm{e}$ \\
\hline PCA-2 & Porto Calvo & $\mathrm{AL}$ & $\mathrm{Ar}$ & cana de açúcar & $0,0 \mathrm{e}$ \\
\hline POM-1 & Pombos & $\mathrm{PE}$ & FrAr & vegetação secundaria & $0,0 \mathrm{e}$ \\
\hline POM-2 & Pombos & $\mathrm{PE}$ & $\mathrm{ArFr}$ & vegetação secundária & $0,0 \mathrm{e}$ \\
\hline PPE-1 & Porto de Pedras & $\mathrm{AL}$ & $\mathrm{ArFr}$ & vegetação secundária & $23,3 \mathrm{c}$ \\
\hline QUE-1 & Queimadas & PB & FrAr & brachiaria & $0,0 \mathrm{e}$ \\
\hline SAN-1 & Santo Antonio & $\mathrm{RN}$ & $\mathrm{ArFr}$ & vegetação secundária & $4,2 \mathrm{~d}$ \\
\hline SJG-1 & São José as Coroa Grande & $\mathrm{PE}$ & $\mathrm{Ar}$ & coqueiro & $0,0 \mathrm{e}$ \\
\hline SJM-1 & São José Mipibu & $\mathrm{RN}$ & $\mathrm{Ar}$ & cana de açúcar & $6,7 \mathrm{~d}$ \\
\hline SOB-1 & Sobrado & $\mathrm{PB}$ & $\mathrm{Ar}$ & mandioca & $0,0 \mathrm{e}$ \\
\hline SOB-2 & Sobrado & PB & $\mathrm{ArFr}$ & abacaxi & $0,0 \mathrm{e}$ \\
\hline SRA-1 & Santa Rita & $\mathrm{PB}$ & $\mathrm{Ar}$ & mata & $3,3 \mathrm{~d}$ \\
\hline SRA-2 & Santa Rita & $\mathrm{PB}$ & $\mathrm{Ar}$ & abacaxi & $0,0 \mathrm{e}$ \\
\hline TEJ-1 & Tejucupapo & $\mathrm{PE}$ & $\mathrm{Ar}$ & cana de açúcar & $0,0 \mathrm{e}$ \\
\hline TIM-1 & Timbaúba & $\mathrm{PE}$ & FrAr & mandioca & $0,0 \mathrm{e}$ \\
\hline VAR-1 & Várzea & $\mathrm{RN}$ & $\mathrm{ArFr}$ & braquiária & $30,4 \mathrm{c}$ \\
\hline
\end{tabular}

${ }^{\mathrm{a} U F}=$ Unidade da federação, $\mathrm{AL}=$ Alagoas, $\mathrm{PB}=$ Paraíba, $\mathrm{PE}=$ Pernambuco, $\mathrm{RN}=$ Rio Grande do Norte; ${ }^{\mathrm{b}} \mathrm{Classe}$ textural: $\mathrm{Ag}=\operatorname{argila}, \mathrm{Ar}=$ areia, $\mathrm{ArFr}=$ areia franca, $\mathrm{FrAr}=$ franco arenoso, $\mathrm{FrAg}=$ franco argiloso, FrAgAr = franco argilo arenoso; ${ }^{\circ}$ Tipo de cobertura do solo na época da coleta; ${ }^{\mathrm{d} C a l c u l a d a}$ considerando o número de talos de feijão-caupi (iscas) que proporcionaram o crescimento de Rhizoctonia no meio de cultura de Ko \& Hora (1971) modificado em relação ao total de talos plaqueados.

Médias originais de oito repetições. Para a realização da análise estatística, os dados foram transformados em $(x+0,5)^{1 / 2}$. Médias seguidas pela mesma letra não diferem significativamente entre si pelo teste de Scott-Knott, ao nível de 5\% de probabilidade. Fonte: Autores.

Todos os crescimentos fúngicos no meio de cultura originados das iscas apresentaram septação das hifas, ramificação em ângulo reto próxima ao septo distal em hifas jovens, presença de septo na ramificação da hifa próximo ao seu ponto de origem, presença de septos do tipo doliporo, ausência de grampos de conexão, ausência de conídios, ausência de rizomorfas, e 
tecido esclerocial não diferenciado em membrana, córtex e medula, características morfológicas típicas de Rhizoctonia (Sneh et al., 1991).

Não houve influência significativa $(\mathrm{P}>0,05)$ do tipo de cobertura do solo na época de coleta e da classe textural dos solos no percentual de colonização saprofítica por Rhizoctonia, apesar da diversidade dos solos estudados.

$\mathrm{Na}$ análise dos possíveis indicadores da supressividade ou conducividade dos solos à atividade saprofítica de Rhizoctonia, foram constatadas correlações positivas significativas $(\mathrm{P} \leq 0,01)$ dessa atividade com os teores de fósforo $(\mathrm{P})(\mathrm{r}=$ 0,80) e potássio $(\mathrm{K})(\mathrm{r}=0,64)$, bem como com a atividade hidrolítica do diacetato de fluoresceína (FDA) $(\mathrm{r}=0,51)$. As demais variáveis químicas, físicas e microbiológicas dos solos não apresentaram correlação significativa com a atividade saprofítica (Tabela 2).

Tabela 2. Correlações entre a atividade (colonização) saprofítica de Rhizoctonia nos solos do Nordeste brasileiro e as variáveis físicas, químicas e microbiológicas dos solos.

\begin{tabular}{lc}
\hline Variável & $\mathbf{r}^{\mathbf{a}}$ \\
\hline Areia (Ar) & $-0,25$ \\
Argila (Ag) & 0,18 \\
Silte (SI) & 0,27 \\
pH (H2O) & 0,09 \\
Fósforo (P) & $0,80^{*}$ \\
Potássio (K) & $0,64^{*}$ \\
Cálcio (Ca) & 0,30 \\
Relação cálcio/magnésio (Ca/Mg) & 0,36 \\
Alumínio (Al) & $-0,04$ \\
Acidez potencial (H+Al) & 0,23 \\
Matéria orgânica (MO) & 0,35 \\
Capacidade de troca catiônica (CTC) & 0,34 \\
Soma de bases (SB) & 0,32 \\
Saturação de bases (V) & 0,37 \\
Saturação por alumínio (m) & $-0,13$ \\
Fungos totais (FTT) & 0,44 \\
Bactérias totais (BTT) & 0,18 \\
Bactérias formadoras de endósporo (BAC) & 0,39 \\
Bactérias oligotróficas (BOL) & 0,29 \\
Bactérias copiotróficas (BCO) & 0,24 \\
CO Ev Evoluído (EVCO ${ }_{2}$ ) & 0,18 \\
Hidrólise do diacetato de fluoresceína (FDA) & $0,51 *$ \\
Atividade de fosfatase ácida (PAC) & 0,37 \\
Índice de diversidade (D) & 0,33 \\
Índice de riqueza (R) & 0,17 \\
Índice de equitabilidade (E) & 0,41 \\
\hline
\end{tabular}

${ }^{a}$ Coeficientes de correlação de Pearson seguidos por asterisco são significativos a $\mathrm{P} \leq 0,01$. Fonte: Autores.

\section{Discussão}

A constatação de atividade saprofítica de Rhizoctonia em quase $40 \%$ dos 52 solos coletados no Nordeste brasileiro indica que esse fungo está amplamente disseminado na região. Como a habilidade de competição saprofítica de Rhizoctonia é uma característica intrínseca e crucial para utilização de substratos e sobrevivência desse parasita facultativo no solo, mesmo na ausência da planta hospedeira (Garrett, 1956), uma elevada atividade saprofítica deve servir como alerta para riscos de epidemias futuras (Papavizas, 1970; Papavizas et al. 1975; Otten et al., 2005; Yulianti et al., 2006). A densidade do inóculo no solo tem sido destacada como um importante aspecto na agressividade de Rhizoctonia, pois mesmo em baixas densidades são induzidos elevados níveis de severidade da doença, indicando a elevada viabilidade e infectividade dos propágulos no solo (Kinsbursky et al., 1988; Phillips, 1989; Schroeder et al., 2008; Brantner et al., 2021). 
Muitos solos do Nordeste brasileiro apresentaram reduzida ou nenhuma atividade saprofítica de Rhizoctonia, sugerindo uma capacidade natural de suprimir essa importante atividade. O potencial de alguns solos prevenirem naturalmente o estabelecimento de patógenos ou inibirem as suas atividades patogênicas, apesar da presença de um patógeno, uma planta hospedeira suscetível e de condições climáticas favoráveis para o desenvolvimento da doença, é denominado supressividade (Baker et al., 1974). Existe diferença entre supressão à doença e supressão ao patógeno. A última é a habilidade de um solo em reduzir a densidade de inóculo do patógeno e sua atividade saprofítica, enquanto a primeira é a capacidade do solo de reduzir a intensidade da doença, mesmo com alta densidade de inóculo e capacidade de sobrevivência do patógeno (Hornby, 1983).

Solos supressivos são comuns em ambientes ecologicamente equilibrados com os ecossistemas em clímax, se os componentes físico-químicos e microbiológicos do solo são estabilizados (Schneider, 1982). Em teoria, quanto maior a complexidade da comunidade biológica do solo, maior é a estabilidade do solo e, consequentemente, o nível do controle biológico natural (Ghini et al., 2006; Jambhulkar et al., 2015). As propriedades físicas, químicas e biológicas do solo podem interferir diretamente na supressividade, por meio do favorecimento da atividade microbiana, ou indiretamente, quando interferem no ciclo do patógeno (Hornby, 1983; Faria et al., 2021). Muitas vezes não é possível estabelecer características específicas e pontuais como sendo exclusivamente responsáveis pelo fenômeno da supressividade dos solos, pois este representa um somatório dos fatores bióticos e abióticos de cada solo (Janvier et al., 2007).

A falta de influência do tipo de cobertura do solo na época de coleta na atividade saprofítica de Rhizoctonia diverge do constatado previamente. Solos cultivados com cana de açúcar, pastagem ou cerrado natural foram mais supressivas a Rhizoctonia que solos com outros tipos de cobertura vegetal (Corrêa et al., 2000). No entanto, estudos de supressividade a Rhizoctonia em variadas coberturas vegetais (Botelho et al., 2001; Ghini et al., 2001; Ghini et al., 2006), constataram que apenas a cobertura vegetal não foi suficiente para explicar que um solo é mais conducivo ou supressivo a Rhizoctonia, tendo em vista que dentro do mesmo grupo de coberturas vegetais, coletados em diferentes pontos, foram observadas variações nas taxas de crescimento e infestação do patógeno.

Em relação à classe textural, diferentemente do constatado nesse estudo, a supressividade a Rhizoctonia tem sido frequentemente associada a solos com textura argilosa (Papavizas, 1970; Alabouvette et al., 1996; Otten et al., 1998, 2006; Gill et al., 2000; Otten et al., 2006; Janvier et al., 2007; Harries et al., 2020). Esses resultados podem ser explicados pelos solos arenosos possuírem maior espaço poroso constituído de macroporos (Gill et al., 2000; Otten et al., 2006), uma vez que o espaço poroso fornece um ambiente em que as interações biológicas, físicas e químicas ocorrem, e através do qual microrganismos e raízes se espalham para interagir e explorar os recursos no solo (Frey, 2015). A divergência nos resultados em relação à classe textural pode ser decorrente das características particulares das populações de Rhizoctonia envolvidas. Em estudo recente (Sousa, 2022), no qual foi avaliada a agressividade de diferentes isolados do patógeno em feijão-caupi em três classes texturais de solo (argilo arenosa, franco argiloso arenosa e franco arenosa), foi constatada a interação significativa entre isolados desse fungo e as texturas do solo. Ou seja, a agressividade dos isolados de Rhizoctonia pode variar conforme a classe textural do solo, bem como a classe textural pode apresentar uma reação variável conforme o isolado.

No presente estudo, ficou demonstrada a importância dos elevados teores de fósforo e potássio no solo no aumento da atividade saprofítica de Rhizoctonia, se comportando como fatores conducivos a essa atividade. Em relação ao fósforo, os resultados divergem do observado por Papavizas et al., (1961), que não constataram a influência da suplementação de fósforo aos substratos na atividade saprofítica de Rhizoctonia. No entanto, em estudo recente (Davey et al., 2021) foi constatado que a aplicação de fósforo na ausência de uma fonte de carbono lábil aumentou a população de Rhizoctonia no solo e a infecção de raízes de trigo. O potássio é requerido para a síntese proteica em plantas e quando deficientes apresentam menor síntese de proteínas e acúmulo de compostos nitrogenados solúveis, como aminoácidos, amidas e nitratos (Malavolta, 2006), sendo estes 
últimos responsáveis por desempenhar um papel favorável ao saprofitismo (Papavizas, 1970). O tombamento de plantas de tomateiro causado por $R$. solani foi negativamente correlacionado com os teores de potássio no solo.

A importância das enzimas do solo se fundamenta no fato de que o funcionamento dos ecossistemas não pode ser entendido corretamente sem a participação dos processos enzimáticos, já que as enzimas determinam, em grande medida, as transformações que ocorrem no solo (Nannipieri et al., 2018). As avaliações da atividade de hidrólise do diacetato de fluoresceína (FDA) e da fosfatase ácida têm sido utilizadas frequentemente para avaliar a atividade microbiana no solo (Melo et al., 2010; Nannipieri et al., 2018). O diacetato de fluoresceína é hidrolisado por várias enzimas (lípases, proteases e esterases) presentes nos microrganismos e, por esse motivo, tem sido usado como sucesso para avaliar a atividade microbiana no solo e como indicador bioquímico de supressividade de solos a Rhizoctonia (Ghini et al., 1998; Bettiol et al., 2005; Ghini \& Morandi, 2006; Bonanomi et al., 2022). Neste estudo, a elevação da atividade FDA no solo evidenciou ser conduciva à atividade saprofítica de Rhizoctonia, assemelhando-se ao constatado em relação ao tombamento de plântulas de tomateiro causado por R. solani (Bonanomi et al., 2022). Por outro lado, os resultados divergem dos observados por Ghini et al., (2006) e Yulianti et al. (2007), que constataram ser a atividade de FDA positiva e altamente correlacionada com a supressão à Rhizoctonia. Possivelmente, os resultados conflitantes estão relacionados aos diferentes níveis de carbono (C) e nitrogênio (N) nos solos, pois na presença de baixa relação $\mathrm{C} / \mathrm{N}$ os resíduos orgânicos são rapidamente degradados no ambiente, gerando rápido estimulo ao desenvolvimento de microrganismos (Ghini et al., 2006), incluindo Rhizoctonia (Papavizas et al., 1961; Papavizas, 1970; Papavizas et al., 1975). A supressão de doenças radiculares é frequentemente categorizada nos tipos geral e específica, sendo a supressão geral associada à atividade microbiana total, que efetivamente compete com os patógenos (Schneider, 1982). No entanto, conforme destacado por Bonanomi et al. (2022), nem sempre a supressividade a Rhizoctonia pode ser explicada por esse modelo baseado na atividade microbiana total utilizando a atividade de FDA no solo como indicadora.

A falta da influência do $\mathrm{pH}$ do solo na atividade saprofítica de Rhizoctonia também surpreendeu, tendo em vista que ótimo saprofitismo ocorre em reação neutra ou ligeiramente alcalina (Papavizas et al., 1961). No entanto, é muito difícil distinguir entre o efeito direto do pH na colonização saprofítica de Rhizoctonia e os efeitos indiretos mediados pelas mudanças físicas, químicas e biológicas nesse ambiente como resultado das mudanças do pH (Papavizas, 1970).

As divergências constatadas nos resultados obtidos nesse estudo em relação à literatura podem ser relacionadas à ampla gama de variações decorrentes dos diferentes tipos de solos e diversidade genética dos isolados de Rhizoctonia, conforme destacado há mais de 50 anos por Papavizas (1970).

\section{Conclusão}

Muitos solos do Nordeste brasileiro encontram-se infestados por Rhizoctonia, o que foi evidenciado pela atividade saprofítica detectada nos mesmos.

A supressividade à atividade saprofítica de Rhizoctonia é influenciada por atributos químicos e biológicos dos solos, que podem ser manipulados para indução da supressividade em solos conducivos.

Há necessidade de novos estudos que avaliem a estabilidade do alto nível de supressão à atividade saprofítica de Rhizoctonia observada em alguns solos do estudo.

\section{Agradecimentos}

Os autores agradecem o apoio de Litervaldo Pereira Machado na coleta das amostras de solo. O presente trabalho foi realizado com apoio da Coordenação de Aperfeiçoamento de Pessoal de Nível Superior - Brasil (CAPES). Sami Jorge Michereff agradece ao Conselho Nacional de Desenvolvimento Científico e Tecnológico - Brasil (CNPq) pela Bolsa de 
Produtividade em Pesquisa.

\section{Referências}

Agarwal, D. K. (2010). Rhizoctonia D.C.: taxonomy, ecology and management. In: Mukerji, K. G. \& Manoharachary, C. (Eds.). Taxonomy and ecology of Indian fungi. New Delhi, I. K. International Publishing House. p.19-50.

Ajayi-Oyetunde, O. O., \& Bradley, C. A. (2018). Rhizoctonia solani: taxonomy, population biology and management of Rhizoctonia seedling disease of soybean. Plant Pathology, 67(1), 3-17.

Alabouvette, C., Hoeper, H., Lemanceau, P. \& C. Steinberg, C. (1996). Soil suppressiveness to disease induced by soilborne plant pathogens. In: Stotzky, G., \& Bollag, J. M. (Eds.). Soil biochemistry. vol. 9, Marcel Dekker: New York. p.371-413.

Anderson, T. H., \& Domsch, K. H. (1990). Application of eco-phisiological quotiens ( $q$ CO2 and $q$ D) on microbial biomasses from soils of different croping histories. Soil Biology and Biochemistry, 22(2), 251-255.

Brantner, J. R., \& Chanda, A. K. (2021). Effects of inoculum density and cultivar susceptibility on rhizoctonia damping-off and crown and root rot in sugar beet. Plant Disease, 105(4), 1019-1025.

Babiker, E. M., Hulbert, S. H., Schroeder, K. L., \& Paulitz, T. C. (2011). Optimum timing of preplant applications of glyphosate to manage Rhizoctonia root rot in barley. Plant Disease, 95(3), 304-310.

Baker, K. F., \& Cook, R. J. (1974). Biological control of plant pathogens. San Francisco: Freeman. 433p.

Baker, R., \& Martinson, C. A. (1970). Epidemiology of diseases caused by Rhizoctonia solani. In: Parmeter Jr., J. R. (Ed.). Rhizoctonia solani: biology and pathology. Berkeley: University of California Press. p.172-188.

Bettiol, W., \& Ghini, R. (2005). Solos supressivos. In: Michereff, S. J., Andrade, D. E. G. T., \& Menezes, M. (Eds.). Ecologia e manejo de patógenos radiculares em solos tropicais. Recife: Universidade Federal Rural de Pernambuco - Imprensa Universitária. p.125-153.

Bonanomi, G., Zotti, M., Idbella, M., Di Silverio, N., Carrino, L., Cesarano, G., Assaeed, A. M., \& Abd-ElGawad, A. M. (2020). Decomposition and organic amendments chemistry explain contrasting effects on plant growth promotion and suppression of Rhizoctonia solani damping off. PLoS ONE, 15(4), e0230925.

Bonanomi, G., Zotti, M., Idbella, M., Cesarano, G., Al-Rowaily, S.L., \& Abd-ElGawad, A. M. (2022). Mixtures of organic amendments and biochar promote beneficial soil microbiota and affect Fusarium oxysporum f. sp. lactucae, Rhizoctonia solani and Sclerotinia minor disease suppression. Plant Pathology, Early View, https://doi.org/10.1111/ppa.13514.

Botelho, A. S., Rava, C. A., \& Leandro, W.M. (2001). Supressividade induzida a Rizoctonia solani pela adição de diferentes resíduos vegetais. Fitopatologia Brasileira, 31(1), 35-42.

Carling, D. E., \& Sumner, D. R. (1992). Rhizoctonia. In: Singleton, L. L., Mihail, J. D. \& Rush, C. M. (Eds.). Methods for research on soilborne phytopathogenic fungi. St. Paul: APS Press. p.157-165.

Chaer, G., Fernandes, M., Myrold, D., \& Bottomley, P. (2009). Comparative resistance and resilience of soil microbial communities and enzyme activities in adjacent native forest and agricultural soils. Microbial Ecology, 58(2), 414-424.

Copley, T. R., Aliferis, K. A., \& Jabaji, S. (2015). Maple bark biochar affects Rhizoctonia solani metabolism and increases damping-off severity. Phytopathology, 105(10), 1334-1346.

Corrêa, G. C., Rocha, M. R., Oliveira Jr, J. P., Carneiro, I. F., \& Cardoso, J. E. (2000). Supressividade de diferentes solos a Rhizoctonia solani, nos cerrados do Estado de Goiás. Pesquisa Agropecuária Tropical, 30(1), 29-33.

Croteau, G. A., \& Zibilske, L. M. (1998). Influence of papermill processing residuals on saprophytic growth and disease caused by Rhizoctonia solani. Applied Soil Ecology, 10(1), 103-115.

Davey, R. S., McNeill, A. M., Barnett, S. J., \& Gupta, V. V. S. R. (2021). Potential for suppression of Rhizoctonia root rot is influenced by nutrient (N and P) and carbon inputs in a highly calcareous coarse-textured topsoil. Soil Research, 59(4), 329-345.

Dhingra, O. D., \& Sinclair, J. B. (1995). Basic plant pathology methods. 2. ed. Boca Raton: Lewis Publishers. 442p.

Donagema, G. K., Campos, D. V. B., Calderano, S. B., Teixeira, W. G., \& Viana, J. H. M. (2011). Manual de métodos de análise de solos. 2. ed. Rio de Janeiro: Embrapa Solos, 2011. 230p.

Faria, M. R., Costa, L. S. A. S., Chiaramonte, J. B., Bettiol, W., \& Mendes, R. (2021). The rhizosphere microbiome: functions, dynamics, and role in plant protection. Tropical Plant Pathology, 46(1), 13-25.

Farr, D. F., \& Rossman, A. Y. (2022). Fungal databases - Fungus-host distributions. Beltsville: USDA - Agricultural Research Service. https://nt.arsgrin.gov/fungaldatabases/fungushost/fungushost.cfm.

Frey, S. D. (2015). The spatial distribution of soil biota. In: Paul, E. A. (Ed.). Soil microbiology, ecology, and biochemistry. 4. ed. New York: Academic Press. p.223-244.

Garland, J. L. (1996). Analytical approaches to the characterization of samples of microbial communities using patterns of potential C source utilization. Soil Biology and Biochemistry, 28(2), 213-221. 
Garrett, S. D. (1956). Biology of root-infecting fungi. Cambridge: Cambridge University Press. 292p.

Garrett, S. D. (1970). Pathogenic root-infecting fungi. London: Cambridge University Press. 308p.

Geoinfo (2014). Mapa de solos do Brasil. Rio de Janeiro: Embrapa Solos. http://geoinfo.cnps.embrapa.br/documents/1032.

Ghini, R., Mendes, M. D. L., \& Bettiol, W. (1998). Utilização do método de hidrólise de diacetato de fluoresceina (FDA) como indicador de atividade microbiana no solo e supressividade a Rhizoctonia solani. Summa Phytopathologica, 24(3-4), 239-242.

Ghini, R., \& Morandi, M. A. B. (2006). Biotic and abiotic factors associated with soil suppressiveness to Rhizoctonia solani. Scientia Agricola, 63(2),153-160.

Ghini, R., \& Zaroni, M. M. H. (2001). Relação entre coberturas vegetais e supressividade de solos a Rhizoctonia solani. Fitopatologia Brasileira, 26(1), 10-15.

Gill, J. S., Sivasithamparam, K., \& Smettem, K. R. J. (2000). Soil types with different texture affects development of Rhizoctonia root rot of wheat seedlings. Plant and Soil, 221(1), 113-120.

Harries, E., Berruezo, L. A., M. Z. Galván, M. Z., Rajal, V. B., \& Mercado Cárdenas, G. E. (2020). Soil properties related to suppression of Rhizoctonia solani on tobacco fields from northwest Argentina. Plant Pathology, 69(1), 77-86.

Hornby, D. (1983). Supressive soils. Annual Review of Phytopathology, 21, 65-85.

Jambhulkar, P. P., Sharma, M., Lakshman, D. \& Sharma, P. (2015). Natural mechanisms of soil suppressiveness against diseases caused by Fusarium, Rhizoctonia, Pythium, and Phytophthora. In: Meghvansi, M. K. \& Varma, A. (Eds.). Organic amendments and soil suppressiveness in plant disease management. Cham: Springer. p.95-123.

Janvier, C., Villeneuve, F., Alabouvette, C., Edel-Hermann, V., Mateille, T., \& Steinberg, C. (2007). Soil health through soil disease suppression: which strategy from descriptors to indicators? Soil Biology and Biochemistry, 39(1), 1-23.

Kinsbursky, R. S., \& Weinhold, A. R. (1988). Influence of soil inoculum density-disease incidence relationship of Rhizoctonia solani. Phytopathology, 78 (1), 127-130.

Ko, W-S., \& Hora, F. K. (1971). A selective media for the quantitative determination of Rhizoctonia solani in soil. Phytopathology, 61(7), 707-712.

Leach, L. D. \& Garber, R. H. (1970). Control of Rhizoctonia. In: Parmeter Jr., J. R. (Ed.). Rhizoctonia solani: biology and pathology. Berkeley: The University of California Press. p.189-199.

Lobo Júnior, M., Souza, J. N. G., \& Santos, A. B. (2004). Processos biológicos e densidade de microrganismos em solo de várzea tropical cultivado com forrageiras para implantação do arroz no sistema plantio direto. Santo Antônio de Goiás: Embrapa Arroz e Feijão. 6p.

Malavolta, E. (2006). Manual de nutrição mineral de plantas. São Paulo: Agronômica Ceres. 638p.

Melo, W. J., Melo, G. M. P., Araújo, A. S. F., \& Melo, V. P. (2010). Avaliação da atividade enzimática em amostras de solo. In: Figueiredo, M. V. B., Burity, H. A., Oliveira, J. P., Santos, C. E. R. S., \& Stamford, N. P. (Eds.). Biotecnologia aplicada à agricultura: textos de apoio e protocolos experimentais. Brasília: Embrapa Informação Tecnológica. p.153-187.

Nannipieri, P., Trasar-Cepeda, C. \& Dick, R. P. (2018). Soil enzyme activity: a brief history and biochemistry as a basis for appropriate interpretations and meta-analysis. Biology and Fertility of Soils, 54(1), 11-19.

Neate, S. M. \& Schneider, H. M. (1996). Sampling and quantification of Rhizoctonia solani in soil. In: Sneh, B., Jabaji-Hare, S., Neate, S., \& Dijst, G. (Eds.). Rhizoctonia species: taxonomy, molecular biology, ecology, pathology and disease control. Dordrecht: Kluwer. p.185-195.

Ogoshi, A. (1987). Ecology and pathogenicity of anastomosis and intraspecific groups of Rhizoctonia solani Kühn. Annual Review of Phytopathology, 25, 125-143.

Ogoshi, A. (1996). Introduction - the genus Rhizoctonia. In: Sneh, B., Jabaji-Hare, S., Neate, S., \& Dijst, G. (Eds.). Rhizoctonia species: taxonomy, molecular biology, ecology, pathology and disease control. Dordrecht: Kluwer. p.1-9.

Otten, W., Filipe, J. A. N., \& Gilligan C. A. (2005). Damping-off epidemics, contact structure, and disease transmission in mixed-species populations Ecology, 86(7), 1948-1957.

Otten, W., \& Gilligan, C. A. (1998). Effect of physical conditions on the spatial and temporal dynamics of the soil borne fungal pathogen Rhizoctonia solani. New Phytologist, 138(4), 629-637.

Otten, W., \& Gilligan, C. A. (2006). Soil structure and soil-borne diseases: using epidemiological concepts to scale from fungal spread to plant epidemics. European Journal of Soil Science, 57 (1), p.26-37.

Papavizas, G. C. (1970). Colonization and growth of Rhizoctonia solani in soil. In: Parmeter Jr., J. R. (Ed.). Rhizoctonia solani: biology and pathology. Berkeley: University of California Press. p.108-122.

Papavizas, G. C., Adams, P. B., Lumsden, R. D., Lewis, J. A., Dow, R. L., Ayers, W. A., \& Kantzes, J. G. (1975). Ecology and epidemiology of Rhizoctonia solani in field soil. Phytopathology, 65(8), 871-877.

Papavizas, G. C., \& Davey, C. B. (1961). Saprophytic behavior of Rhizoctonia in soil. Phytopathology, 51(8), 693-699.

Paulitz, T. C., \& Schroeder, K. L. (2005). A new method for the quantification of Rhizoctonia solani and R. oryzae from soil. Plant Disease, 89(7), 767-772. 
Research, Society and Development, v. 11, n. 3, e34311326477, 2022

(CC BY 4.0) | ISSN 2525-3409 | DOI: http://dx.doi.org/10.33448/rsd-v11i3.26477

Phillips, A. J. L. (1989). Relationship of Rhizoctonia solani inoculum density to increase of hypocotyl rot and damping-off in dry beans. Canadian Journal of Microbiology, 35(10), 1132-1140.

Sanfuentes, E., Alfenas, A. C., Maffia, L. A., \& Maffia, R. G. (2007). Flutuação populacional de Rhizoctonia spp. em jardim clonal de Eucalyptus spp. Fitopatologia Brasileira, 32(2), 114-120.

Schneider, R. W. (1982). Suppressive soils and plant disease. St Paul: APS Press. 88p.

Schroeder, K. L., \& Paulitz, T. C. (2008). Effect of inoculum density and soil tillage on the development and severity of Rhizoctonia root rot. Phytopathology, 98(3), 304-314

Schruner, J., \& Rosswall, T. (1982). Fluorescein diacetate hydrolysis as a measure of total microbial activity in soil and litter. Applied and Environmental Microbiology, 43(6), 1256-1261.

Sneath, P. H. (1986). Endospore-forming gram-positive cods and cocci. In: Sneath, P. H (Ed.). Bergey's manual of systematic bacteriology. Baltimore: Williams \& Wickins. v. 2, p.1104-1207.

Sneh, B., Burpee, L., \& Ogoshi, A. (1991). Identification of Rhizoctonia species. St. Paul: APS Press. 133p.

Sousa, D. Y. X. (2022). Fatores influenciando a agressividade de isolados de grupos de anastomose de Rhizoctonia associados com feijão-caupi. Monografia (Graduação em Agronomia) - Universidade Federal do Cariri, Crato. 46p.

Spurlock, T., Rothrock, C., \& Monfort, W. (2015). Evaluation of methods to quantify populations of Rhizoctonia in soil. Plant Disease, 99(6), 836-841.

Tabatabai, M. A. (1994). Soil enzymes. In: Weaver, R. W. (Ed.). Methods of soil analysis. Part 2: Microbiological and biochemical properties. Madison: Soil Science Society of America. p.778-833.

Tótola, M. R., \& Chaer, G. M. (2002). Microrganismos e processos microbiológicos como indicadores da qualidade dos solos. Tópicos em Ciência do Solo, v. 2, p.195-276.

Tuite, J. (1969). Plant pathological methods - Fungi and bacteria. Minneapolis: Burgess. 239p.

Yang, G., \& Li, C. (2012). General description of Rhizoctonia species complex. In: Cumagun, C. J. R. (Ed.). Plant pathology. Rijeka: Intech. p.41-52.

Yulianti, T., Sivasithamparam, K., \& Turner D. W. (2006). Saprophytic growth of Rhizoctonia solani Kühn AG2-1 (ZG5) in soil amended with fresh green manures affects the severity of damping-off in canola. Soil Biology and Biochemistry, 38(9), 923-930.

Yulianti, T., Sivasithamparam, K., \& Turner D. W. (2007). Saprophytic and pathogenic behavior of R. solani AG2-1(ZG-5) in a soil amended with Diplotaxis tenuifolia or Brassica nigra manures and incubated at different temperatures and soil water content. Plant and Soil, 294 (2), $277-289$.

Zak, J. C. (1994). Functional diversity o microbial communities: a quantitative approach. Soil Biology and Biochemistry, 26(9), 1101-1108. 